\title{
TREATMENT OF IDIOPATHIC SCOLIOSIS BY HARRINGTON INSTRUMENTATION
}

\author{
Bajracharya A R ${ }^{1}$, Chhetri $\mathbf{R ~ S}^{1}$ \\ Kharel $\mathbf{Y} \mathbf{R}^{1}$, Chalise $\mathbf{P}^{1}$, Rai $\mathbf{P}^{1}$, Giri $\mathbf{S} \mathbf{K}^{1}$
}

ABSTRACT

An adolescent idiopathic right-sided thoracolumbar scoliosis has been corrected surgically with Harrington distraction and compression instrumentation with posterior fusion for the first time in Nepal.

Key Words: Idiopathic scoliosis, Harrington system.

\section{INTRODUCTION}

Idiopathic scoliosis is the commonest of all types of scoliosis. It is divided into infantile, juvenile and adolescent types according to the age of onset. It is estimated that using 5 and 10 degrees as cutoff points, the prevalence of scoliosis in general population was 6.58 and 2.4 per cent, respectively.

Scoliosis is probably the earliest evident deformity which mankindhad faced. ${ }^{1}$ Hippocrates was the first person to use the name "Skoliosis" for any curvature of the spine and originated method of treatment. ${ }^{2}$ Now, the term is confined to the lateral curvature of the spine. Over the thousand years later, Paul of Agina attempted gradual scoliosis correction by binding the body to corrective splints. At the turn of last century, in 1914, Russell Hibbs performed the first scoliosis spine fusion at the old New York Orthopedic Hospital. ${ }^{3}$ Afterwards, in 1946 Drs Blunt and Schmidt of Milwaukee deigned the Milwaukee brace, which has been mainstay in the non-operative treatment of scoliosis.

1. Bir Hospital, Kathmandu, Nepal.

Address for correspondence : Dr. Ashok R. Bajracharya

Department of Orthopaedics

Bir Hospital, Kathmandu

Nepal. 


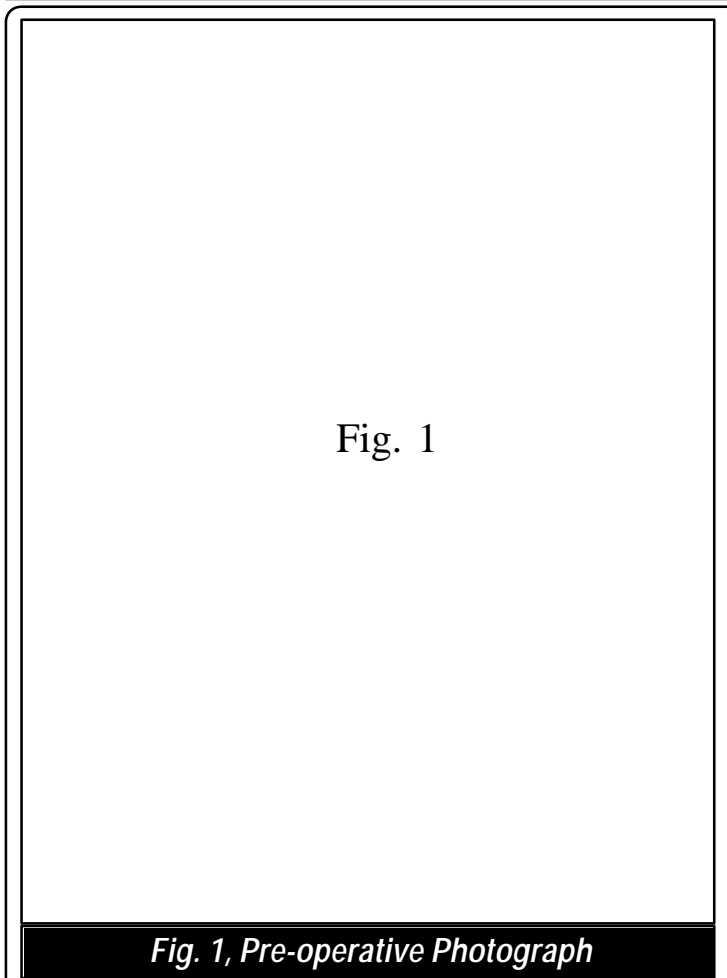

The Harrington System, in 1962, revolutionized the surgical correction of this deformity. Alan Dwyer of Australia devised an anterior approach to the thoracic and lumbar spine. Edwardo Luque from Mexico City designed the "segmental spinal instrumentation". Cotrel and Dubousset have introduced a system where cast, brace were not required post operatively. However, only the Harrington Rod Instrumentation system was available in Kathmandu implant market, when this operation was carried out.

\section{CASE REPORT}

A fifteen years old school girl, SG, from Shankhuwashava presented two years ago with increasing deformity of her back of three years duration. She was diagnosed to have right-sided thoracolumbar adolescent idiopathic scoliosis and was being treated conservatively. In spite of conservative treatment her scoliotic deformity gradually increased and started having back pain. There was no family history of scoliosis. On examination her standing height was $125 \mathrm{~cm}$ and sitting height was $60 \mathrm{~cm}$, trunk alignment examined by dropping a plumb line was "out of balance". Her neurological status was normal. Her cardio-pulmonary and renal functions were found normal. Roentogenographic evaluation: The Upper end vertebra was a dorsal $7^{\text {th }}$, lower end vertebra was lulnbar $2^{\text {nd }}$, and the apical vertebra was dorsal $17^{\text {th }}$. Cobb angle measured 50 degree. She had King's type III scoliosis. Her skeletal maturity status

Fig. 2

Fig. 2

Left
Fig. 2

Centre
Fig. 2

Right 
was Risser V. There was some rotational deformity of the dorsolumbar spine as well. However there were no compensatory curves.

MRI showed no spinal cord anomalies.

Operation: Under the preoperative X-ray control, spine was approached posteriorly from dorsal $5^{\text {h }}$ vertebra to lumbar $5^{\text {th }}$ vertebra exposing spinous processes. Keeping interspinous and supraspinous

\section{Fig. 3, Post-operative Check X-ray}

ligaments intact, laminae, pedicle and transverse process were exposed. Harrington distraction instrumentation was applied by placing upper hook on dorsal $7^{\text {th }}$ vertebral facet and lower hook on lumbar $2^{\text {nd }}$ vertebral lamina of the concave side and Harrington's compression instrumentation was applied by placing upper hook at transverse process of $9^{\text {th }}$ dorsal spine and lower hook at lamina of $1^{\text {st }}$ lumber vertebrae of the convex side after soft tissue and facet joint release .On both sides, Interlaminar and intrarticular fusions of facet joints were done with cortiococancelleous bone graft taken from posterior ileum. Stagnara wake-up test was performed after correction of deformity to confirm intactness of the neurological status before closure of the wound. Postoperatively underarm thermoplastic brace was applied. Operative and postoperative periods were uneventful. She was kept at ICU for 4 days postoperatively. She was mobilized on $4^{\text {th }}$ postoperative day onwards.
Stitches were removed on $14^{\text {th }}$ post operative day. Her standing height increased to $127 \mathrm{~cm}$ and sitting height to $62 \mathrm{~cm}$. Her neurological status was normal. Postoperatively the residual Cobb angle measured 19 degree.

\section{DISCUSSION}

Scoliosis surgery is the ultimate in spinal surgery. This is a high technology demanding surgery that needs appropriate infrastructure including special operating equipment instruments \& implants, specialized anesthesia, intensive postoperative care (ICU) and surgical technical know how besides routine care. Exhaustive preoperative preparation and planning is necessary. Now, all these have become available at Bir Hospital with some indigenous modification. At our department, Spinal surgery is being practiced as a superspeciality besides the general orthopedics and trauma since over 12 yrs. So far we have 5 more scoliosis cases on regular follow up. Understanding the condition, it's treatment and willingness to be operated after knowing the benefits and risks, on the patient' part and readiness of the operating team, the theatre and indoor set up on the other side are extremely important for a successful scoliosis surgery. Because lot of dedication and preparation efforts are required for this surgery. Both these sides clicked in this case and hence the successful surgery.

The reasons we operated upon her were

1. The increasing backache

2. Progressive objectionable deformity on her back

3. Cobb's angle more than 45 degree and

4. The strong possibility of further progression during pregnancy in future.

Although better and sophisticated instrumentations are available these days elsewhere, we barely managed to have access to the Harrington instrumentation only, in Kathmandu. Availability of implants especially in 
a developing country like Nepal, is a big dictating factor upon the choice of instrumentation.

Full correction to 0 degree Cobb`s angle although desirable is not necessary. Beside normally also up to 20 degree of scoliosis is found among normal population that is detected only in screening programme. Attempt at full surgical correction without spinal cord monitoring device is a bit risky. The Stagnara wake-up test is a crude method of assessing the spinal cord function in absence of the spinal cord monitoring device. Postoperatively the amount of correction achieved was 30 degree in lateral curvature and 31 degree of kyphosis in this case.

At the outset questions on the success of the operation were raised by different quarters. Hence we reported it only after patient went home and have come back few times for follow up. We consider it to be successful because

1. There was no intra-operative and post operative complications.

2. The patient and party are fully satisfied with the result.

3. The corrections achieved were in lateral curvature as well as kyphosis resulting in increment of height.

\section{ACKNOWLEDGEMENTS}

The authors acknowledge the superb efforts of Dr. Kamala Suwal, Dr. Chhatra Krishna Shrestha and Dr. Govinda Joshi to provide safe anesthesia and Stagnara wake-up test during surgery.
The authors also thank scrub nurses Bharati, Rameshwori and sister Dilmaya on the floor, for their coordinated assistance. Radiographer D P Neupane for providing X-ray control over the entire operation and Orthotist Gyanendra Shrestha for application of immediate postoperative thermoplastic underarm brace at the operation theatre itself. The authors express their sincere thanks to the patient and her guardians who gave consent for surgical intervention fully knowing that the surgery was going to be undertaken for the first time in Nepal and their cooperation in rehabilitation program.

\section{REFERENCE}

1. A dam $G$ reenspam. $S$ coliosis and $A$ nomalies with general affection of the skeleton, orthopaedics $R$ adiology, $A$ practical approach, $P$ hiladel phia, $K$.B . L ippincott 1988, P P 26:3-28.

2. H ugo $A, K$ eim. C linical and roentegenographic evaluation of the scoliosis patient. $T$ he $A$ dol escent S pine. $N$ ew $Y$ ork $S$ pring- $V$ erleg 1982. P P . 137151.

3. $\mathrm{H}$ ugo $\mathrm{A}, \mathrm{K}$ eim. $\mathrm{S}$ coliosis. T headolescent $\mathrm{S}$ pine, $\mathrm{N}$ ew Y ork S pring-verleg. 1982, P P 107-137.

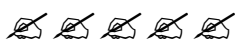

